\title{
Cranberry Derived Proanthocyanidins Reduce Bacterial Adhesion to Selected Biomaterials
}

\author{
Revised and resubmitted to:
}

Langmuir

June 16, 2008

IRWIN ADAM EYDELNANT and NATHALIE TUFENKJI*

Department of Chemical Engineering, McGill University, Montreal, Quebec H3A 2B2, Canada

*Corresponding Author. Phone: (514) 398-2999; Fax: (514) 398-6678; E-mail: nathalie.tufenkji@mcgill.ca 


\begin{abstract}
Catheter associated urinary tract infections (CAUTI) linked with the uropathogens Escherichia coli (E. coli) and Enterococcus faecalis (E. faecalis) account for the majority of nosocomial infections acquired in the clinical environment. Because these infections develop following initial adhesion of the bacterial pathogens to the catheter surface, there is increased interest in developing effective methods to inhibit attachment of cells to biomaterials used in the manufacture of indwelling devices. High molecular weight proanthocyanidins (PAC) extracted from the North American cranberry (Vaccinium macrocarpon) were examined for their potential to reduce the initial adhesion of uropathogenic bacteria (E. coli CFT073 and E. faecalis 29212) to two model biomaterials, poly(vinyl chloride) (PVC) and polytetrafluoroethylene (PTFE). Well-controlled experiments conducted in a parallel-plate flow chamber (PPFC) demonstrated decreased attachment of both bacteria to PVC and PTFE when either the bacteria, biomaterial or both surfaces were treated with PAC. Most significant inhibition of bacterial adhesion was observed for the condition where both the bacteria and biomaterial surfaces were coated with PAC. Additional experiments conducted with non-biological model particles demonstrate comparable extents of adhesion inhibition, supporting a non-biospecific mechanism of PAC action. The results of this study are promising for the implementation of PAC in the clinical milieu for prevention of device associated infection as the proposed functional modification is independent of anti-bacterial mechanisms that may give rise to resistant strains.
\end{abstract}




\section{Introduction}

Microbial contamination of invasive medical devices causes a broad spectrum of nosocomial pathologies (e.g., urinary tract infection, lower respiratory tract infection, etc). The initial adhesion of pathogens to biomaterials is the first in a series of steps leading to the development of device associated infection (DAI), acting as a major obstacle in the extended use of devices ranging from urinary catheters to cardiac pacemakers ${ }^{1}$. Catheter associated urinary tract infections (CAUTI) account for the majority of nosocomial infections acquired in hospitals and nursing homes ${ }^{2}$. In 2002, the National Nosocomial Infections Surveillance system in the United States identified approximately 1.7 million cases of nosocomial infection that resulted in nearly 100,000 patient deaths. CAUTI accounted for nearly one-third of these cases, leading to more than 13,000 deaths ${ }^{2}$. Two-thirds of CAUTI incidents progress from extraluminal contamination, either directly during catheter insertion, or by perineal microbes ascending along the mucous film contiguous with the external catheter surface ${ }^{3}$. The leading infective microorganisms isolated from CAUTI catheters are Escherichia coli (E. coli) and Enterococcus faecalis (E. faecalis), together accounting for more than $40 \%$ of all CAUTI infections ${ }^{3}$. Colonization of urinary catheters by uropathogenic organisms leads to the formation of biofilms that have been associated with the onset of urinary tract infection (UTI) ${ }^{4,5}$. Yet, current antibiotic regimes are often ineffective at halting biofilm formation and potentiate the development of multidrug resistant bacteria. As a result, alternative treatments are required that inhibit bacterial adhesion processes and shift therapeutic strategies from bacteriocidal to functional modifications.

DAI begins with the initial adhesion of pathogenic microorganisms on biomaterial surfaces. Lifshitz-van der Waals (LW) forces and electrical double layer (EL) forces have been recognized as the predominant physicochemical forces that control particle or bacteria 
interactions with solid surfaces in aqueous media ${ }^{6,7}$. The Derjaguin-Landau-Verwey-Overbeek (DLVO) theory provides a framework to account for the contributions of these forces in the interpretation of bacteria-surface interactions ${ }^{8,9}$. Researchers have used the classical DLVO or "extended" DLVO (XDLVO) approach in attempts to describe microbial adhesion to a broad range of substrates, including glass, sand, and polymers ${ }^{10-18}$. In DLVO theory, the total interaction energy between a bacterial cell and a solid surface is considered the sum of the noncovalent LW and EL forces. As the separation distance between the cell and the solid increases, EL forces decay exponentially, whereas LW forces decay more gradually. The DLVO approach is useful in qualitatively describing cell adhesion onto solid surfaces; however results of bacterial adhesion experiments are not always in agreement with theoretical predictions ${ }^{11,13,18}$. Such deviations from DLVO theory have been partly attributed to the complexity and heterogeneity of bacterial cell surfaces ${ }^{18,} 19$. This inherent constitutional complexity of bacterial surfaces, combined with variability across different strains and species, contribute to the difficulty in generalizing findings regarding the mechanisms of microbial adhesion to solid substrates.

An understanding of bacterial interaction with and adherence to mammalian cells is also of significant importance as it is often the first stage in bacterial disease ${ }^{20}$. A broad range of biomolecules and macromolecular structures (i.e., fimbrial and afimbrial adhesins) are involved in controlling bacterial adhesion to mammalian cell surfaces or receptors ${ }^{20}$. For instance, in the development of UTI, E. coli adhere to uroepithelial cells via type 1 and P-fimbriae, which attach to mannose specific receptors and alpha-D-Gal(1-4)-beta-D-Gal, respectively ${ }^{20,21}$. Several studies have demonstrated how the implementation of bioactive components of the North American cranberry (Vaccinium macrocarpon) or cranberry juice may inhibit the onset of UTI by preventing attachment of uropathogenic bacteria to uroepithelial cells $\mathrm{s}^{22-26}$. Ahuja et $\mathrm{al}^{26}$ found 
that cells of $E$. coli grown in media supplemented with cranberry juice lost expression of Pfimbriae leading to a loss in fimbrial adhesion. Characterization of bacterial surfaces using atomic force microscopy (AFM) in the presence and absence of cranberry juice indicated conformational changes in the macromolecules at the cell surface ${ }^{27}$. Other studies have shown that P-fimbriated E. coli lose the ability to adhere to bladder cells following pre-incubation with (i) urine of humans who had consumed cranberry juice cocktail ${ }^{24,28}$, (ii) commercially available cranberry powder ${ }^{23}$, or (iii) proanthocyanidins (PACs) extracted from cranberry fruit ${ }^{23,}{ }^{28}$. Cranberry derived PACs have been found to have unique A-type linkages ${ }^{29}$ which are believed to play a key role in the anti-adhesive properties of these compounds ${ }^{25,30}$. Although previous studies demonstrate that cranberry derived products can prevent adhesion of $E$. coli to eucaryotic cells $^{23,24,31,32}$, silicone rubber $^{33}$ and glass ${ }^{34,35}$, the mechanism(s) by which cranberry alters the adhesion of bacteria are not well understood.

In this study, we investigate whether bacterial adhesion to common biomaterials can be reduced by treatment with cranberry derived PACs. Due to its prevalence, we have selected catheter associated urinary tract infection (CAUTI) as a model pathology for investigation. Using a parallel-plate flow chamber (PPFC), we examined the influence of PAC on the adhesion of both Gram negative and Gram positive uropathogenic bacteria to two common biomaterials used in the manufacture of urinary catheters; namely, poly(vinyl chloride) (PVC) and polytetrafluoroethylene (PTFE). Our results demonstrate the effectivity of these high molecular weight tannins in the reduction of bacterial adhesion to common biomaterials independent of antibacterial mechanisms. To elucidate the mechanism of PAC action we investigated changes in cell and biomaterial surface properties following PAC treatment. The experimental data 
suggests a physical mechanism of steric interference further supported by evidence that PAC treatment significantly reduces the adhesion of non-biological model colloids to biomaterials.

\section{Materials and methods}

\subsection{Bacterial cell preparation.}

Uropathogenic E. coli ATCC 700928 (more commonly known as CFT073) and E. faecalis ATCC 29212 were used in this study. E. coli CFT073 is a Gram negative clinical isolate from the blood and urine of a woman with acute pyelonephritis and its complete genome has been sequenced $^{36}$. E. faecalis ATCC 29212 is a well-characterized Gram-positive uropathogenic bacterium isolated from urine. Pure cultures were maintained at $-80{ }^{\circ} \mathrm{C}$ in Luria-Bertani Lennox broth $(20 \mathrm{~g} / \mathrm{L})$ supplemented with $30 \%$ glycerol. Cultures were streaked onto LB agar plates that were then incubated for $24 \mathrm{~h}$ at $37{ }^{\circ} \mathrm{C}$. For each experiment, a single colony from a fresh plate was used to inoculate $50 \mathrm{~mL}$ of $\mathrm{LB}$ broth (in a $150 \mathrm{~mL}$ Erlenmeyer flask). Cultures were incubated at $37^{\circ} \mathrm{C}$ for $17 \mathrm{~h}$ at $200 \mathrm{rpm}$, then harvested by centrifugation at $5860 \mathrm{~g}$ for $15 \mathrm{~min}$ (SS-34 rotor, Kendro) at $4{ }^{\circ} \mathrm{C}$. The growth medium was decanted and the pellet was resuspended in phosphate buffered saline (PBS, $137 \mathrm{mM} \mathrm{NaCl}, 2.7 \mathrm{mM} \mathrm{KCl}, 10 \mathrm{mM} \mathrm{Na} 2 \mathrm{HPO}_{4}$, $1.8 \mathrm{mM} \mathrm{KH}_{2} \mathrm{PO}_{4}$ ). Centrifugation and resuspension were repeated one additional time to remove any traces of growth media and metabolites. The concentration of the cell suspension was determined with a Helber (SV400, Proscitech) bacteria counting chamber and the suspensions were diluted accordingly to the desired final concentration of $1 \times 10^{8} \mathrm{CFU} / \mathrm{mL}$ in PBS (pH 7.4). Analytical reagent grade chemicals (Fisher) and deionized (DI) (Milli-Q) water were used to prepare all solutions and media. 
In selected experiments conducted to determine the effect of PAC on bacterial adhesion and bacterial surface properties, the final cell dilution was prepared using PBS supplemented with cranberry derived solubilized PACs $(100 \mu \mathrm{g} / \mathrm{mL})$. Briefly, dry PAC extract with an average molecular weight of $15 \mathrm{kDa}$ (obtained from A.B. Howell, Rutgers) was solubilized in DI to obtain a PAC stock solution $(1.5 \mathrm{mg} / \mathrm{mL})$. PAC supplemented PBS (PAC-PBS, $100 \mu \mathrm{g} / \mathrm{mL}$ ) was then prepared by adding an appropriate volume of the PAC stock to PBS.

\subsection{Bacterial cell characterization.}

Microelectrophoresis (ZetaSizer Nano ZS, Malvern) was used to characterize the electrokinetic properties of the cells in PBS and PAC-PBS. Electrophoretic mobility (EPM) was measured at $22{ }^{\circ} \mathrm{C}$ using cell suspensions $\left(1 \times 10^{7}\right.$ cells $\left./ \mathrm{mL}\right)$ prepared in either diluent. These measurements were repeated using at least three different samples (prepared from separate cultures) of each bacterial suspension. Measured EPMs were converted to cell zeta potential using the Smoluchowski equation ${ }^{37}$.

Individual components of bacterial surface free energies were determined from contact angle measurements on bacterial films with the polar liquids water and formamide and the apolar liquid diiodomethane. Contact angle measurements (sessile drop technique, OCA 20, Future Digital Scientific) were conducted on bacterial lawns formed on a cellulose acetate membrane filter $\left(0.45 \mu \mathrm{m}, 47 \mathrm{~mm}\right.$ diameter, GE Osmonics) using the method described in ref ${ }^{38}$. At least four measurements were made on each filter, and at least three filters were used for each condition at ambient temperature $22^{\circ} \mathrm{C}$.

The nominal size of the bacteria was determined by analyzing images taken in an inverted fluorescent microscope (IX-71, Olympus) operating in phase contrast mode. An image 
processing program (ImageJ, NIH) was used to determine the average lengths of the major and minor axes of the cells and the resulting equivalent spherical diameter.

\subsection{Bacterial cell viability.}

Plate counts were used to verify loss of cell viability when suspended in PAC-PBS. Cell suspensions were diluted in High Recovery Diluent (Oxoid), spread plated on R2A agar (Difco; in triplicate) and incubated for 24 hours $\left(37^{\circ} \mathrm{C}\right)$ before counting.

\subsection{Bacteria and particle adhesion experiments.}

Initial bacterial adhesion to two common biomaterials was examined using a dual channel parallel plate flow chamber (PPFC) (dimensions, $\mathrm{L} \times \mathrm{W} \times \mathrm{H}=39.5 \times 13 \times 0.32 \mathrm{~mm}$, Model FC271, Biosurface Technologies). Clean unplasticized PVC or PTFE disks (diam. 14 mm, Biosurface Technologies) were mounted in the flow cell and the system was equilibrated with PBS using a syringe pump (Model 200, KD Scientific) at $0.5 \mathrm{~mL} / \mathrm{min}$ for a duration of $10 \mathrm{~min}$. Bacterial suspensions $\left(1 \times 10^{8} \mathrm{CFU} / \mathrm{mL}\right)$ were then injected into the flow cell $(0.5 \mathrm{~mL} / \mathrm{min}, 10$ $\mathrm{min})$, followed by an equivalent injection of PBS alone $(0.5 \mathrm{~mL} / \mathrm{min}, 10 \mathrm{~min})$ to remove any unbound cells from the system. The PVC or PTFE disks were then carefully removed from the flow cell (avoiding passage through an air-liquid interface that can cause removal of attached cells), stained with DAPI (4',6-diamidino-2-phenylindole) $(100 \mu \mathrm{L}$ at $100 \mu \mathrm{g} / \mathrm{mL})$ and incubated in the dark for 10 min. The PVC or PTFE disks were then imaged by fluorescence microscopy (IX-71, Olympus), and the attached bacteria were enumerated with image analysis software (ImagePro). Four separate treatments were used in the adhesion experiments: (i) control: bacteria suspended in PBS were injected into the flow cell; (ii) bacteria only treated with PAC: 
bacteria were resuspended in PAC-PBS $(100 \mu \mathrm{g} / \mathrm{mL})$ for a duration of 10 min to allow PAC adsorption onto the cell surfaces, the suspension was centrifuged, the supernatant decanted, and cells were resuspended in PBS prior to injection in the flow cell; (iii) biomaterials only treated with PAC: prior to injecting the bacteria into the flow cell, a PAC-PBS solution $(100 \mu \mathrm{g} / \mathrm{mL})$ was injected $(0.5 \mathrm{~mL} / \mathrm{min}, 10 \mathrm{~min})$ to allow adsorption of the PAC onto the biomaterial surface, followed by injection of PBS alone $(0.5 \mathrm{~mL} / \mathrm{min}, 10 \mathrm{~min})$ and finally a suspension of bacteria in PBS; (iv) biomaterials and bacteria treated with PAC: bacteria resuspended in PAC-PBS (100 $\mu \mathrm{g} / \mathrm{mL}$ ) were directly injected into the flow cell, allowing the PAC to adsorb both on the bacteria surface and the biomaterial surface. These experiments were conducted with the two bacteria selected (E. coli CFT073 and E. faecalis). To better understand the mechanism by which PAC influences the initial adhesion of the bacteria, an additional set of flow cell experiments was conducted using fluorescent blue sulfate latex microspheres (Invitrogen, Eugene, OR). The microspheres were selected to be similar in size to the bacteria (1.0 $\mu \mathrm{m}$ diam.) and experiments were conducted for the four treatments described above using a microsphere concentration of $1 \times 10^{7}$ particles $/ \mathrm{mL}$. All bacteria and microsphere adhesion experiments were conducted at ambient temperature $\left(22^{\circ} \mathrm{C}\right)$ and repeated at least 4 times.

\subsection{Characterization of biomaterials.}

The zeta potential of the PVC and PTFE substrates was determined by streaming potential analysis conducted on thin rectangular coupons made from the same materials (Biosurface Technologies). The rectangular coupons were mounted inside a PPFC (Model FC81, Biosurface Technologies) of comparable dimensions to the one described in section 2.4, but specially designed for thin rectangular coupons $(\mathrm{L} \times \mathrm{W} \times \mathrm{H}=40.6 \times 11.4 \times 0.203 \mathrm{~mm})$. After 
mounting a coupon inside the flow cell, the coupon was equilibrated with PBS (control) or PACPBS (to allow adsorption of PAC onto the biomaterial) for $10 \mathrm{~min}(0.5 \mathrm{~mL} / \mathrm{min})$. The treated coupon was then removed from the flow cell and mounted in the clamping cell of a streaming potential analyzer (EKA, Brookhaven Instruments Corp., NY). The streaming potential measurements were conducted by pumping PBS across the biomaterial surface as described in ref ${ }^{39}$. The biomaterial zeta potentials were determined from the measured streaming potentials using the analysis presented by Walker et $\mathrm{al}^{39}$.

Individual components of biomaterial surface free energies were determined from contact angle measurements on the biomaterial coupons as described above for bacterial films. Contact angle measurements (sessile drop technique, OCA 20, Future Digital Scientific) were conducted on PVC or PTFE coupons after they had been equilibrated with PBS or PAC-PBS for 10 min as described above. At least four measurements were made on each coupon (at ambient temperature $22^{\circ} \mathrm{C}$ ), and at least two coupons were used for each condition.

\subsection{Adsorption of cranberry proanthocyanidins onto biomaterials.}

A quartz crystal microbalance with dissipation monitoring (QCM-D) was used to verify adsorption of cranberry derived PACs onto a biomaterial surface (note: only unplasticized PVC coated quartz crystals were available from the manufacturer). The QCM-D E4 unit (Q-Sense AB, Västra Frölunda, Sweden) consists of a measurement chamber platform that can hold 4 sensor flow modules. Each flow module holds a $5 \mathrm{MHz}$ AT-cut quartz sensor crystal with a PVC coated surface and is configured such that the flow is parallel to the crystal surface (as in the parallel plate flow cell). Prior to mounting in the flow modules, the PVC coated crystals were soaked in DI and dried with ultra-high purity $\mathrm{N}_{2}$ gas. The clean dry crystals were mounted 
in a flow chamber, and PBS was drawn through the chamber with a peristaltic pump (150 $\mu \mathrm{L} / \mathrm{min}$, Reglo-Digital, Ismatec) until baseline was achieved (i.e., the measured change in frequency was less than $1 \mathrm{~Hz} /$ hour $)$. PAC-PBS $(100 \mu \mathrm{g} / \mathrm{mL})$ was then drawn through the chamber for $35 \mathrm{~min}(150 \mu \mathrm{L} / \mathrm{min})$, followed by a $15 \mathrm{~min}$ injection of $\mathrm{PBS}(150 \mu \mathrm{L} / \mathrm{min})$. Finally, a mild detergent (1\% Hellmanex in DI, $300 \mathrm{~mL} / \mathrm{min}, 10 \mathrm{~min}$ ) was drawn through the chamber until the resonance frequency returned to the baseline value. During the QCM-D experiment, the temperature inside the measurement chamber was maintained at $22{ }^{\circ} \mathrm{C}$. The thickness and density of the adsorbed PAC film were assumed to be uniform. Analysis of the QCM-D data was done using the Q-Tools program (Q-Sense AB).

\subsection{Statistical analysis.}

Results were reported as means \pm standard deviation (SD) for all experiments and were analyzed using a Student's t-test. A p-value $<0.01$ was considered statistically significant.

\section{Results and discussion}

\subsection{Influence of PAC on cell viability}

One motivation for using cranberry derived PAC in the prevention of device associated infection lies in its potential action as an anti-adhesive compound independent of antibacterial mechanism that may lead to the development of resistance. Antibacterial properties have previously been reported at PAC concentrations greater than $200 \mu \mathrm{g} / \mathrm{mL}$ while anti-adhesive effects have been observed at concentrations as low as $5 \mu \mathrm{g} / \mathrm{mL}^{23}$. In the present study, a working concentration of $100 \mu \mathrm{g} / \mathrm{mL}$ was selected and verified for any effects on bacterial viability during the timescale of the experiments. When bacteria were grown in LB then resuspended and incubated in PAC-PBS 
for $30 \mathrm{~min}$, there were no significant differences in viability as determined by plate counting. For $E$. coli, the plate count after $30 \mathrm{~min}$ of incubation in PAC-PBS was $1.4 \pm 0.2 \times 10^{8} \mathrm{CFU} / \mathrm{mL}$, in comparison to $1.4 \pm 0.1 \times 10^{8} \mathrm{CFU} / \mathrm{mL}$ when suspended in PBS alone for $30 \mathrm{~min}$. Similarly, for E. faecalis, the plate count after $30 \mathrm{~min}$ of incubation in PAC-PBS was $1.3 \pm 0.2 \times 10^{7}$ $\mathrm{CFU} / \mathrm{mL}$, in comparison to $1.2 \pm 0.2 \times 10^{7} \mathrm{CFU} / \mathrm{mL}$ when suspended in PBS alone for $30 \mathrm{~min}$. Hence, at the working concentration of PAC used in this study, the cranberry derived compound does not have antibiotic effects, thereby reducing selective pressures for antibiotic resistant bacteria.

\subsection{Effect of PAC on bacteria and biomaterial properties}

Several studies have demonstrated that bacterial surface properties can control the extent of bacterial attachment to inert surfaces ${ }^{15,40-42}$. Although the current body of knowledge does not allow generalization of findings regarding the influence of a specific cell property on bacterial adhesion, measurable cell surface characteristics such as hydrophobicity and surface potential (charge) have been linked with adhesion onto surfaces such as glass ${ }^{11,41}$, polymers ${ }^{15,43,44}$, and silica $^{40,45}$. To examine the effects of PAC on the physicochemical properties of the selected bacteria and biomaterials, experiments were conducted to evaluate changes in the relative hydrophobicity of the bacteria and materials, as well as variations in surface potential before and after exposure to cranberry derived PAC.

Sessile drop contact angle measurements conducted on dried microbial lawns are widely used to characterize the relative hydrophobicity of microbial cell surfaces ${ }^{12,44,46}$. Contact angle measurements conducted on dried lawns of E. coli and E. faecalis as well as the two biomaterials were used to determine the various components of surface tension using equations 4 and 5 (Table 
1). Both bacterial strains were found to be hydrophilic $\left(\theta_{\mathrm{w}}<90^{\circ}\right)$, with PAC treatment resulting in an increase in E. coli hydrophobicity but no significant effect on E. faecalis. Ionic and polar groups on surfaces lead to an increased affinity for water and may inhibit adhesion due to hydrophilic effects. An increase in cell surface hydrophobicity has often been associated with increased bacterial adhesion to both hydrophobic and hydrophilic surfaces ${ }^{44,45}$. Contact angle measurements conducted on the surface of untreated and PAC treated biomaterials revealed that both substrates are generally hydrophobic $\left(\theta_{\mathrm{w}}\right.$ close to or greater than $\left.90^{\circ}\right)$. Exposure to PAC resulted in lower water contact angles for both PVC and PTFE.

\section{[TABLE 1 HERE]}

All measurements conducted on bacterial films demonstrated relatively low values for the electron donating components of surface energy, ranging from $0.7 \mathrm{~mJ} / \mathrm{m}^{2}$ for E. faecalis to 2.5 $\mathrm{mJ} / \mathrm{m}^{2}$ for PAC treated E. coli, yielding total surface tensions dominated by Lifshitz-van der Waals interactions. Similarly, Lifshitz-van der Waals interactions accounted for nearly the entire measured surface tension of the biomaterials where electron donating components were between $0 \mathrm{~mJ} / \mathrm{m}^{2}$ for PTFE and PVC, and $0.9 \mathrm{~mJ} / \mathrm{m}^{2}$ for PAC treated PVC. Moreover, all bacterial surfaces were determined to be higher energy than biomaterial surfaces, a property reflective of hydrophilic bacteria and hydrophobic substrata.

Table 1 also includes a summary of the zeta potentials $(\zeta)$ of the two bacteria and the two biomaterials, measured in PBS at $\mathrm{pH}$ 7.4. The two strains of bacteria and the two inert substrates are negatively charged in the presence and absence of PAC and the data shows no significant change in bacteria or biomaterial $\zeta$ with PAC treatment. 
The equivalent spherical radii of the two cell types were determined by image analysis of microscope images taken before and after exposure to PAC (Table 1). The data shows that no significant differences in size exist between the PAC treated and untreated bacteria. E. coli were slightly rod shaped and formed some aggregates with an average equivalent spherical radius of $1.76 \mu \mathrm{m}$. In contrast, E. faecalis were typically cocci generally found in pairs with an average equivalent spherical radius of $0.75 \mu \mathrm{m}$. Measured zeta potentials, contact angles, and bacterium sizes are used later to calculate interaction energy profiles for the different bacteria-biomaterial systems using two models of colloid-surface interactions; the DLVO model and the Steric model (details provided in Supporting Information).

\subsection{PAC adsorption onto PVC}

To verify whether PAC was readily adsorbed on a biomaterial surface, a QCM installed with PVC coated quartz sensor crystals was used. The QCM measures changes in the resonance frequency of the sensor crystal as mass is added or removed from the crystal surface ${ }^{47,48}$. As increased mass adsorbs on the crystal surface, the shift in the resonance frequency increases proportionally, as described by the Sauerbrey relationship ${ }^{47,}{ }^{48}$. Fig. 1a shows the measured frequency shift of the PVC coated crystal as it is equilibrated with PBS (phase I), PAC-PBS is flowed over the crystal surface (phase II), followed by an equivalent injection of PBS alone (phase III). The rapid and substantial change in resonance frequency $(f)$ upon injection of the PAC-PBS suggests that the PVC is readily coated with PAC. In phase IV of the experiment, the adsorbed PAC layer is rapidly removed by injecting a mild detergent solution and the baseline

resonance frequency of the crystal is recovered. By assuming a PAC film density of $1050 \mathrm{~kg} / \mathrm{m}^{3}$ on the crystal surface, and considering the Sauerbrey model, the frequency measurements in 
Figure 1a can be converted to mass adsorbed on the surface. Fig. 1b shows the data from the QCM experiment in terms of nanograms per square centimeter of crystal surface. The PAC coverage is approximately $600 \mathrm{ng} / \mathrm{cm}^{2}$ which corresponds to a film thickness of about $5 \mathrm{~nm}$.

[FIGURE 1 HERE]

\subsection{Adhesion of E. coli and E. faecalis onto PVC and PTFE}

Parallel plate flow cell experiments were performed to determine the effectivity of PAC in preventing the initial adhesion of bacteria to biomaterial surfaces. Fig. 2 summarizes the results of the bacterial adhesion experiments conducted with both biomaterials, where the four treatments are indicated as follows: (i) control (CTRL), (ii) bacteria only treated with PAC (BAC); (iii) biomaterial only treated with PAC (MAT), and (iv) biomaterials and bacteria treated with PAC (BOTH). Overall, the data shows that PAC reduced bacterial attachment under all conditions, whether only the biomaterial or bacteria or both surfaces had been treated. In Fig. 2a, the results show 1.6 and 1.5-fold reductions in the extent of E. coli 700928 attached to PVC when either the substrate or the bacteria is treated with PAC, respectively. Similarly, 1.7 and 1.8-fold reductions in attached E. coli cells were observed for experiments conducted with PTFE when either the material or the cells were treated with PAC. When both the bacteria and the biomaterial were PAC treated, the extent of E. coli attachment to PVC and PTFE was 1.8 and 2.1-fold lower, respectively. To our knowledge, this is the first evidence that PAC has the ability to inhibit the adhesion of uropathogenic E. coli to biomaterials.

The effects of PAC were even more pronounced when E. faecalis 29212, a representative Gram-positive microorganism, was tested (Fig. 2b). Results of experiments examining the 
influence of PAC on E. faecalis adhesion reveal 2.0-fold and 1.4-fold reductions in the extent of bacterial adhesion onto PVC when either the biomaterial (MAT) or the microorganism (BAC) is treated with cranberry PAC, respectively (Fig. 2b). Experiments conducted with E. faecalis and PTFE show an even greater effect, whereby the extent of bacterial attachment decreases by $56 \%$ when the biomaterial is treated with PAC prior to injection of the bacteria into the PPFC. When both the bacteria and the biomaterial were PAC treated, the reduction in E. faecalis adhesion to PVC and PTFE was 90\% and 88\% lower, respectively. This is also the first evidence of PAC preventing the adhesion of a Gram-positive microorganism. For both bacteria-biomaterial systems, maximum inhibition of adhesion occurred when both the biomaterial and the bacteria were treated with PAC, suggesting that the compound was acting at both surfaces. This new evidence of PAC functioning independent of the Gram staining of the bacteria is suggestive of non-specific mechanisms of action, unlike those previously suggested in the literature with respect to adhesion of $E$. coli to mammalian cells ${ }^{22,23}$.

\section{[FIGURE 2 HERE]}

\subsection{Examining the mechanism(s) by which PAC prevents bioadhesion}

To investigate the likelihood of a non-specific mechanism of action for PAC, PPFC experiments were repeated using latex microspheres instead of bacteria, thereby eliminating any biospecific effects. Experiments were conducted for all four treatments, as was described previously for the bacteria. Interestingly, the attachment behavior observed using the microspheres was very similar to that observed for the cells, particularly, with E. faecalis (Fig.

3). Representative microscope images of the biomaterial surface (PTFE) following PPFC 
experiments conducted with the latex microspheres are presented in Fig. 4. The images reveal clear differences in the number of attached latex microspheres on the PTFE surface in the absence and presence of PAC. The summarized results shown in Fig. 3 reveal reductions in the extent of adhesion ranging from 1.2 to 5.8-fold. The observed significant influence of PAC on a non-biological particle demonstrates that, at least in part, non-biospecific mechanisms account for its antiadhesive properties on biomaterials. Furthermore, in contrast to the results obtained with the two bacteria, PAC treatment resulted in lower absolute values of zeta potential for the latex particles (Table 1). Within the context of the classical DLVO theory of colloidal stability, a particle with a lower absolute potential will experience a lower extent of electrostatic repulsion upon approach to an oppositely charged surface, thereby leading to a greater extent of attachment $^{8,9,49}$. However, the opposite behavior is observed in Fig. 3, whereby the degree of particle deposition onto the biomaterial surfaces is lower in the presence of PAC. This observation suggests that PAC effects are not electrostatically mediated at the conditions examined here.

[FIGURE 3 HERE]

[FIGURE 4 HERE]

To better understand the mechanisms controlling the observed bacterial deposition behavior, the DLVO and Steric models (described in Supporting Information) were used to calculate bacteriabiomaterial interaction energies. Fig. 5a shows representative DLVO interaction energy profiles for the E.coli-PVC system, where the total interaction energy $\left(V^{\mathrm{T}}\right)$ was evaluated as the sum of equations 1 and 7. The calculations reveal no energy barrier to deposition in the primary energy 
minimum for all four treatments (note that the energy profiles all fall on the same curve). Hence, based on the DLVO interaction energy calculations, the E. coli is expected to deposit extensively on the PVC surface under all conditions examined. Despite these DLVO predictions, E. coli adhesion is high in the absence of PAC but much lower when both the biomaterial and the bacteria are treated with PAC. Table 2 summarizes the key parameters estimated using the DLVO model for the four different bacteria-biomaterial systems; namely, the maximum height of the energy barrier $\left(V_{\mathrm{b}}\right)$, and the Hamaker constant $(A)$. The DLVO model predicts no energy barrier to adhesion for all four systems, under all conditions examined. Yet, the data presented in Figure 2 reveal distinct variations in the bacterial adhesion behavior when PAC is used to treat one or both surfaces. Clearly, the observed E. coli and E. faecalis deposition behavior in the presence of the cranberry derived PACs is not well described by the DLVO model alone.

[FIG. 5 HERE]

[TABLE 2 HERE]

Steric stabilization is a well-known phenomenon in colloid literature ${ }^{42,50-53}$. Adsorbed layers of polymer (such as cranberry derived PAC) on the surfaces of biocolloids (e.g., bacteria) or collector surfaces (e.g., biomaterials) can give rise to steric interactions upon approach of the cell to the biomaterial surface. To evaluate the potential role of steric interactions in the four bacteria-biomaterial systems, the Steric model was used to estimate the overall interaction energy profiles for all experimental conditions considered.

Representative interaction energy profiles calculated using the Steric model (sum of equations 1, 7, and 11) for the E. coli-PVC system are presented in Fig. 5b. The graph shows 
significantly different predictions from those evaluated using the DLVO model. Most clearly, calculated heights of the energy barrier $\left(V_{\mathrm{b}}\right)$ are extremely high when PAC is used to treat at least one of the surfaces (bacteria or biomaterial). Values of $V_{\mathrm{b}}$ calculated using the Steric model for the four different bacteria-biomaterial systems are summarized in Table 2. When steric interactions $\left(V^{\mathrm{ST}}\right)$ are considered, the calculated heights of the energy barrier $\left(V_{\mathrm{b}}\right)$ are significant for PAC conditions whereas no energy barrier is predicted for the control conditions (for all four bacteria-biomaterial systems). These calculations based on the Steric model can be used qualitatively to better understand the observed cell adhesion behavior; namely, higher energy barriers are generally predicted under conditions where less bacterial adhesion is observed (Figure 2). For example, for the case of E. faecalis, the Steric model predicts larger barriers to adhesion (on the order of 82,200 to $86,200 k T$ ) for the dual treatment condition ("BOTH") in contrast to the conditions where only one (bacteria or biomaterial) or no surface was treated with PAC (values range from 77,300 to $81,300 k T$ ). Accordingly, the treatment with the lowest number of attached E. faecalis cells is that where both the bacteria and the biomaterial surfaces are treated with PAC (Fig. 2b). Likewise, the greatest extent of E. faecalis adhesion is observed for the control condition where no energy barrier to deposition is expected (for both biomaterials examined). The two remaining treatments ("BAC" and "MAT") exhibit cell attachment in between that observed for the "CTRL" and "BOTH" conditions, and correspondingly, lower values of $V_{\mathrm{b}}$ than the "BOTH" treatment. A similar trend is observed in the calculations for the interaction of E. coli with either biomaterial; namely, the largest calculated energy barrier is associated with the "BOTH" treatment which exhibits the least amount of adhesion (Table 2 and Figure 2a). Comparison of the experimental adhesion data (Fig. 2) with theoretical predictions of bacteria-biomaterial interaction energies based on the two models (Table 2) suggests that 
steric stabilization may be an important mechanism by which PAC inhibits bacterial adhesion to inert surfaces. Namely, the calculations demonstrate that DLVO interactions alone can not be used to interpret the experimental results, but rather a mechanism of steric hindrance must be invoked to explain the observed trends in bacterial adhesion.

While the measured extent of bacterial adhesion in the presence of PAC is generally in qualitative agreement with estimated heights of the energy barriers based on the Steric model, it should be noted that values of $V_{\mathrm{b}}$ determined using the Steric model are generally on the order of $77,300 k T$ or greater (when an energy barrier is present) (Table 2). However, bacteria are not theoretically capable of overcoming repulsive energy barriers of such magnitude. Theoretically, bacteria are expected to deposit on surfaces (i.e., overcome the repulsive energy barrier) where $V_{\mathrm{b}}$ is on the order of 0 to $25 \mathrm{kT}$. Despite these predictions, however, bacterial adhesion is observed even when both surfaces are treated with PAC and energy barriers are on the order of $77,300 k T$ or greater. These very high energy barriers to attachment predicted by the theoretical calculations suggest that bacteria must be retained on the biomaterial surface by a mechanism other than deposition in the primary energy minimum of the interaction energy profile.

There is increasing evidence in the literature pointing to the importance of the secondary energy minimum in controlling particle and microbial deposition onto inert surfaces ${ }^{11,}$ 18, 54-56. The secondary energy well in the bacteria-surface interaction energy profile is located at a greater separation distance than that of the repulsive energy barrier. In Fig. 5c, where the Steric model interaction energy profiles are replotted on a different scale, we note the presence of a secondary energy well for each PAC treatment (note: the calculations for the BAC and MAT treatments fall on the same curve). Table 3 summarizes the predicted depths of the secondary energy well based on calculations using the Steric model. Because the heights of the repulsive 
energy barrier are so great, it is much more likely that the bacteria are being first retained in the secondary energy minimum prior to transitioning to the primary energy minimum ${ }^{18}$. Indeed, the observed bacterial adhesion behaviour (Fig. 3) is generally in qualitative agreement with the predicted depths of the secondary energy minimum, whereby deeper wells are associated with a greater extent of adhesion (for each bacteria-biomaterial system). For instance, in the case of $E$. faecalis interacting with PTFE, the shallowest secondary energy well (39kT) is linked with the lowest extent of adhesion ("BOTH" treatment), whereas the deepest secondary minimum $(111 k T)$ is associated with a greater number of attached cells ("BAC" treatment). The same trend is followed for the three other bacteria-biomaterial systems. The data in Table 3 also indicate that the deeper energy wells are located at smaller separation distances $(h)$, thereby facilitating bacterial attachment to the biomaterial surface. An earlier investigation suggests that bacteria retained in a secondary energy well are readily washed away in a flow system because of their freedom to move laterally with respect to the substratum ${ }^{14}$. However, in a more recent study, de Kerchove and Elimelech ${ }^{18}$ used a novel technique to provide direct evidence of irreversible deposition of particles or cells entrapped in the secondary energy minimum, despite the hydrodynamic forces arising from the radial flow in their experimental impinging jet system. These recent findings and the significant depths of the secondary minima determined here (Table 3) support our hypothesis that bacteria are being retained in a secondary energy well where they may transition to the primary energy minimum.

[TABLE 3 HERE] 
Although the depths of the secondary energy well (and heights of the repulsive energy barrier) are in qualitative agreement with the experimental data, a few inconsistencies can still be observed in the overall trends. These inconsistencies may be attributed to the influence of surface charge heterogeneities on the bacteria or biomaterial surface, or nonhomogeneous coverage of the bacteria and/or biomaterial surfaces by the cranberry derived PAC. In this work, continuum models of biocolloid-surface interactions (e.g., DLVO) based on macroscopic measurements of bacterial and material surface properties are used to better understand the adhesion behavior of bacteria to biomaterials. It should be noted, however, that these comparisons of experimental adhesion data with DLVO and Steric model calculations may be considered mostly qualitative in nature as they do not include the influence of microbe specific properties (e.g., lipopolysaccharides and proteins on the cell surface). Several studies ${ }^{19,57-59}$ have demonstrated the importance of molecular-scale details on microbial adhesion and these could also account for some of the observed inconsistencies with the theoretical models considered here. Moreover, it can be noted that the models utilized here require assumptions about the values of several parameters (e.g., in equations 1,2 and 7) which are not definitively known for the system in question. Nevertheless, the general qualitative trends in the model calculations provide useful information for better understanding of the role of cranberry derived PACs in bacterial adhesion to biomaterials.

\section{Conclusions}

Cranberry derived proanthocyanidins are shown to be effective in the reduction of initial adhesion of uropathogens to the biomaterials PTFE and PVC, commonly used in the manufacture of urinary catheters. We have demonstrated, for the first time, the action of 
cranberry PACs against a Gram-positive organism and a non-biological particle (latex microsphere). These results suggest that a non-biospecific physical mechanism prevents the bacteria and microspheres from adhering to the biomaterial surfaces. Comparison of the experimental data with theoretical predictions of bacteria-biomaterial interaction energies calculated using the DLVO and Steric models further supports a mechanism of steric stabilization due to adsorption of PAC on both biomaterial and microbe surfaces. Importantly, we have shown that PAC acts in such a way that viability of the microorganisms is not negatively affected, thereby reducing selective pressures for resistant bacteria. Although the application of cranberry proanthocyanidin at the dose used in this study does not completely eliminate bacterial adhesion, the simplicity of the adsorption process to biomaterial surfaces and the nonspecificity of the proposed mechanism make the use of PAC in the treatment of medical devices quite promising. The clinical implementation of this natural system has the potential to decrease financial expenditures related to device associated infection and improve patient care. Further research is being pursued in our laboratory to explore the use of PAC in preventing biofilm formation on various materials. 


\section{Acknowledgements}

This research was supported by NSERC (Discovery Grant), the Cranberry Institute, the Wisconsin Cranberry Board and the CRC and CFI Programs. The authors acknowledge A. B. Howell (Rutgers) for providing cranberry derived proanthocyanidins, A. Manges (McGill) for providing E. coli CFT073, K. Harmidy for assistance with bacteria characterization, and S. Khan for assistance with material characterization. We thank two anonymous reviewers for comments that improved the manuscript.

\section{Supporting Information}

Details regarding theoretical models used in the analysis. This information is available free of charge via the Internet at http://pubs.acs.org. 


\section{References}

1. $\quad$ Darouiche, R. O. Clinical Infectious Diseases 2001, 33 (9), 1567-1572.

2. $\quad$ Klevens, R. M.; Edwards, J. R.; Richards, C. L.; Horan, T. C.; Gaynes, R. P.; Pollock, D. A.;

Cardo, D. M. Public Health Reports 2007, 122 (2), 160-166.

3. $\quad$ Maki, D. G.; Tambyah, P. A. Emerging Infectious Diseases 2001, 7 (2), 342-347.

4. $\quad$ Trautner, B. W.; Darouiche, R. O. AJIC 2004, 32 (3), 177-183.

5. $\quad$ Costerton, J. W.; Stewart, P. S.; Greenberg, E. P. Science 1999, 284 (5418), 1318-1322.

6. $\quad$ Van Oss, C. J., Interfacial Forces in Aqueous Media. 2nd ed.; CRC Press: 2006.

7. Bos, R.; van der Mei, H. C.; Busscher, H. J. Fems Microbiology Reviews 1999, 23 (2), 179-230.

8. Derjaguin, B. V.; Landau, L. D. Acta Physicochim. URSS 1941, 14, 733-762.

9. Verwey, E. J. W.; Overbeek, J. T. G., Theory of the Stability of Lyophobic Colloids. Elsevier: Amsterdam, 1948.

10. Simoni, S. F.; Bosma, T. N. P.; Harms, H.; Zehnder, A. J. B. Environmental Science \& Technology 2000, 34 (1011-1017).

11. Azeredo, J.; Visser, J.; Oliveira, R. Colloids and Surfaces B: Biointerfaces 1999, 14, 141-148.

12. Triandafillu, K.; Balazs, D. J.; Aronsson, B.-O.; Descouts, P.; Quoc, P. T.; van Delden, C.;

Mathieu, H. J.; Harms, H. Biomaterials 2003, 24, 1507-1518.

13. Tufenkji, N. Water Resources Research 2006, 42 (12), W12S11.

14. Redman, J. A.; Walker, S. L.; Elimelech, M. Environmental Science \& Technology 2004, 38, $1777-1785$.

15. Roosjen, A.; Busscher, H. J.; Norde, W.; Van der Mei, H. C. Microbiology 2006, 152, 26732682.

16. Emerson, R. J.; Camesano, T. A. Appl. Environ. Microbiol. 2004, 70, 6012-6022.

17. Abu-Lail, N. I.; Camesano, T. A. Environmental Science \& Technology 2003, 37, 2173-2183.

18. de Kerchove, A. J.; Weronski, P.; Elimelech, M. Langmuir 2007, 23, 12301-12308.

19. Walker, S. L.; Redman, J. A.; Elimelech, M. Langmuir 2004, 20, 7736-7746.

20. Finlay, B. B.; Cossart, P. Science 1997, 276 (5313), 718-725.

21. Duguid, J.; Old, D., Adhesive properties of Enterobacteriaceae. In Bacterial Adherence,

Receptors and Recognition, Beachey, E., Ed. Chapman \& Hall: London, 1980; pp 185-217.

22. Howell, A. B.; Vorsa, N.; Der Marderosian, A.; Foo, L. Y. New England Journal of Medicine 1998, 339 (15), 1085-1086.

23. Gupta, K.; Chou, M. Y.; Howell, A. B.; Wobbe, C.; Grady, R.; Stapleton, A. E. Journal of Urology 2007, 177, 2357-2360.

24. Di Martino, P.; Agniel, R.; David, K.; Templer, C.; Gaillard, J. L.; Denys, P.; Botto, H. World Journal of Urology 2006, 24, 21-27.

25. Howell, A. B. Molecular Nutrition \& Food Research 2007, 51, 732-737.

26. Ahuja, S.; Kaack, B.; Roberts, J. Journal of Urology 1998, 159, 559-562.

27. Liu, Y.; Black, M. A.; Caron, L.; Camesano, T. A. Biotechnology and Bioengineering 2006, 93, 297-305.

28. Howell, A. B.; Foxman, B. Journal of the American Medical Association 2002, 287 (23), 3082.

29. Foo, L. Y.; Lu, Y.; Howell, A. B.; Vorsa, N. Phytochemistry 2000, 54, 173-181.

30. Howell, A. B.; Reed, J. D.; Krueger, C. G.; Winterbottom, R.; Cunningham, D. G.; Leahy, M. Phytochemistry 2005, 66, 2281-2291.

31. Burger, O.; Ofek, I.; Tabak, M.; Weiss, E. I.; Sharon, N.; Neeman, I. FEMS Immunology and Medical Microbiology 2000, 29, 295-301.

32. Zafriri, D.; Ofek, I.; Adar, R.; Pocino, M.; Sharon, N. Antimicrobial Agents and Chemotherapy 1989, 33 (1), 92-98.

33. Habash, M. B.; Van der Mei, H. C.; Busscher, H. J.; Reid, G. Canadian Journal of Microbiology 1999, 45, 691-694. 
34. Johnson-White, B.; Buquo, L.; Zeinali, M.; Ligler, F. S. Analytical Chemistry 2006, 78, 853-857.

35. Allison, D. G.; Cronin, M. A.; Hawker, J.; Freeman, S. J. Basic Microbiology 2000, 40 (1), 3-6.

36. Welch, R. A.; Burland, V.; Plunkett, I. G.; Redford, P.; Roesch, P.; Rasko, D.; Buckles, E. L.; Liou, S.-R.; Boutin, A.; Hackett, J.; Stroud, D.; Mayhew, G. F.; Rose, D. J.; Zhou, S.; Schwartz, D. C.; Perna, N. T.; Mobley, H. L. T.; Donnenberg, M. S.; Blattner, F. R. Proc. Natl. Acad. Sci. USA 2002, 99 (26), 17020-17024.

37. Hunter, R. J., Foundations of Colloid Science. Oxford University Press: New York, 2001; p 806.

38. Busscher, H. J.; Weerkamp, A. H.; van der Mei, H. C.; van Pelt, A. W. J.; de Jong, H. P.; Arends, J. Applied and Environmental Microbiology 1984, 48 (5), 980-983.

39. Walker, S. L.; Bhattacharjee, S.; Hoek, E. M. V.; Elimelech, M. Langmuir 2002, 18, 2193-2198.

40. $\quad$ Castro, F. D.; Tufenkji, N. Environmental Science \& Technology 2007, 41, 4332-4338.

41. Jucker, B. A.; Zehnder, A. J. B.; Harms, H. Environmental Science \& Technology 1998, 32, 2909-2915.

42. Rijnaarts, H. H. M.; Norde, W.; Lyklema, J.; Zehnder, A. J. B. Colloids and Surfaces BBiointerfaces 1999, 14 (1-4), 179-195.

43. van Loosdrecht, M. C. M.; Lyklema, J.; Norde, W.; Schraa, G.; Zehnder, A. J. B. Applied and Environmental Microbiology 1987, 53 (8), 1898-1901.

44. $\quad$ van Loosdrecht, M. C. M.; Lyklema, J.; Norde, W.; Schraa, G.; Zehnder, A. J. B. Applied and Environmental Microbiology 1987, 53 (8), 1893-1897.

45. Jacobs, A.; Lafolie, F.; Herry, J. M.; Debroux, M. Colloids and Surfaces B: Biointerfaces 2007, $59,35-45$.

46. Gallardo-Moreno, A. M.; Gonzalez-Martin, M. L.; Bruque, J. M.; Perez-Giraldo, C.; SanchezSilos, R. J. Adhesion Sci. Technol. 2003, 17 (14), 1877-1887.

47. Sauerbrey, G. Zeitschrift fiir Physik 1959, 155, 206-222.

48. Hook, F.; Rodahl, M.; Brzezinski, P.; Kasemo, B. Langmuir 1998, 14, 729-734.

49. Elimelech, M.; Gregory, J.; Jia, X.; Williams, R. A., Particle Deposition and Aggregation: Measurement, Modelling, and Simulation. Butterworth-Heinemann: Oxford, England, 1995; p 441.

50. Woodle, M. C.; Lasic, D. D. Biochimica et Biophysica Acta 1992, 1113, 171-199.

51. Rijnaarts, H. H. M.; Norde, W.; Lyklema, J.; Zehnder, A. J. B. Colloids and Surfaces B:

Biointerfaces 1995, 4 (4), 191-197.

52. Tufenkji, N.; Dixon, D. R.; Considine, R.; Drummond, C. J. Water Research 2006, 40, 33153331.

53. Napper, D. H. Journal of Colloid and Interface Science 1977, 58 (2), 390-407.

54. Kuznar, Z. A.; Elimelech, M. Colloids and Surfaces A: Physicochem. Eng. Aspects 2007, 294, 156-162.

55. Hahn, M. W.; Abadzic, D.; O'Melia, C. R. Environmental Science \& Technology 2004, 38, 59155924.

56. Litton, G. M.; Olson, T. M. Colloids and Surfaces A-Physicochemical and Engineering Aspects 1996, 107, 273-283.

57. Salerno, M. B.; Logan, B. E.; Velegol, D. Langmuir 2004, 20, 10625-10629.

58. Burks, G. A.; Velegol, S. B.; Paramonova, E.; Lindenmuth, B. E.; Feick, J. D.; Logan, B. E. Langmuir 2003, 19, 2366-2371.

59. $\quad$ Considine, R. F.; Drummond, C. J.; Dixon, D. R. Langmuir 2001, 17, 6325-6335. 
Table 1. Summary of bacteria and biomaterial surface properties in the presence and absence of PAC

\begin{tabular}{|c|c|c|c|c|c|c|c|c|c|c|c|}
\hline & \multicolumn{3}{|c|}{ Contact Angle $\left({ }^{\circ}\right)^{\mathrm{a}}$} & \multicolumn{5}{|c|}{ Surface Tension Components $\left(\mathrm{mJ} / \mathrm{m}^{2}\right)$} & \multirow{2}{*}{$\frac{\mathrm{EPM}}{(\mu \mathrm{m} \mathrm{cm} / \mathrm{Vs})}$} & \multirow{2}{*}{$\frac{\zeta}{(\mathrm{mV})}$} & \multirow{2}{*}{$\frac{a_{\mathrm{p}}}{(\mu \mathrm{m})}$} \\
\hline & $\theta_{\mathrm{w}}$ & $\theta_{\mathrm{f}}$ & $\theta_{\mathrm{m}}$ & $\gamma^{T}$ & $\gamma^{L W}$ & $\gamma^{A B}$ & $\gamma^{+}$ & $\gamma^{-}$ & & & \\
\hline \multicolumn{12}{|l|}{ Organism/Particle } \\
\hline E. coli & $24(2.6)$ & $22(2.6)$ & $51(4.6)$ & 53.7 & 33.9 & 9.9 & 2.0 & 48.5 & $-1.96(0.2)$ & $-21.8(1.7)$ & $1.75(0.5)$ \\
\hline E. coli $+P A C$ & $49(3.0)$ & $30(5.6)$ & $49(4.3)$ & 50.4 & 35.0 & 7.7 & 2.5 & 24.1 & $-2.08(0.1)$ & $-23.1(0.6)$ & $1.77(0.5)$ \\
\hline E. faecalis & $26(5.7)$ & $33(7.7)$ & $49(2.2)$ & 47.1 & 34.7 & 6.2 & 0.7 & 54.7 & $-1.38(0.1)$ & $-15.3(0.7)$ & $0.79(0.2)$ \\
\hline E. faecalis $+P A C$ & $24(3.1)$ & $25(4.3)$ & $50(1.5)$ & 52.4 & 34.5 & 9.0 & 1.6 & 50.4 & $-1.41(0.1)$ & $-15.7(1.0)$ & $0.70(0.1)$ \\
\hline Latex & - & - & - & - & - & - & - & - & $-2.83(0.2)$ & $-39.2(2.1)$ & - \\
\hline Latex $+P A C$ & - & - & - & - & - & - & - & - & $-1.48(0.1)$ & $-20.5(0.6)$ & - \\
\hline \multicolumn{12}{|l|}{ Biomaterial } \\
\hline$P V C$ & $87(3.9)$ & $79(3.4)$ & $45(3.3)$ & 36.7 & 36.7 & 0.0 & 10.5 & 0.0 & - & $-24.9(4.0)$ & - \\
\hline$P V C+P A C$ & $66(3.4)$ & $55(5.9)$ & $45(1.9)$ & 38.7 & 37.0 & 4.1 & 19.1 & 0.9 & - & $-28.3(3.9)$ & - \\
\hline$P T F E$ & $108(2.5)$ & $92(4.3)$ & $53(6.5)$ & 32.3 & 32.3 & 0.0 & 1.4 & 0.0 & - & $-29.2(3.9)$ & - \\
\hline$P T F E+P A C$ & $95(1.3)$ & $73(4.7)$ & $92(4.3)$ & 28.9 & 27.7 & 0.2 & 1.5 & 0.6 & - & $-30.3(4.5)$ & - \\
\hline
\end{tabular}

${ }^{a}$ Contact angles were measured using water $\left(\theta_{\mathrm{w}}\right)$, formamide $\left(\theta_{\mathrm{f}}\right)$, and diiodomethane $\left(\theta_{\mathrm{m}}\right)$.

${ }^{\mathrm{b}}$ The values in parentheses are standard deviations. 
Table 2. Summary of energy barriers estimated using DLVO and Steric models

Estimated Energy Barriers $\left(V_{\mathrm{b}}\right)$ and Hamaker Constants $(A)$

\begin{tabular}{|c|c|c|c|c|c|c|c|c|}
\hline \multirow{3}{*}{ Bacteria-Biomaterial System } & \multicolumn{8}{|c|}{ Treatment } \\
\hline & \multicolumn{2}{|c|}{$\mathrm{CTRL}^{\mathrm{a}}$} & \multicolumn{2}{|c|}{ BAC } & \multicolumn{2}{|c|}{ MAT } & \multicolumn{2}{|c|}{ BOTH } \\
\hline & $\begin{array}{c}V_{\mathrm{b}} \\
(k T)\end{array}$ & $\begin{array}{c}A \\
(J) \\
\end{array}$ & $\begin{array}{c}V_{\mathrm{b}} \\
(k T) \\
\end{array}$ & $\begin{array}{c}A \\
(J) \\
\end{array}$ & $\begin{array}{c}V_{\mathrm{b}} \\
(k T) \\
\end{array}$ & $\begin{array}{c}A \\
(J) \\
\end{array}$ & $\begin{array}{c}V_{\mathrm{b}} \\
(k T) \\
\end{array}$ & $\begin{array}{c}A \\
(J) \\
\end{array}$ \\
\hline \multicolumn{9}{|l|}{ E. coli-PVC } \\
\hline DLVO model ${ }^{\mathrm{c}}$ & $0^{\mathrm{b}}$ & $3.0 \times 10^{-20}$ & 0 & $3.0 \times 10^{-20}$ & 0 & $3.0 \times 10^{-20}$ & 0 & $3.0 \times 10^{-20}$ \\
\hline Steric model ${ }^{\mathrm{d}}$ & - & $3.0 \times 10^{-20}$ & 186,200 & $3.0 \times 10^{-20}$ & 187,000 & $3.0 \times 10^{-20}$ & 197,700 & $3.0 \times 10^{-20}$ \\
\hline \multicolumn{9}{|l|}{ E. coli-PTFE } \\
\hline DLVO model & 0 & $2.9 \times 10^{-20}$ & 0 & $2.9 \times 10^{-20}$ & 0 & $2.7 \times 10^{-20}$ & 0 & $2.8 \times 10^{-20}$ \\
\hline Steric model & - & $2.9 \times 10^{-20}$ & 190,800 & $2.9 \times 10^{-20}$ & 199,400 & $2.7 \times 10^{-20}$ & 207,300 & $2.8 \times 10^{-20}$ \\
\hline \multicolumn{9}{|l|}{ E. faecalis- $P V C$} \\
\hline DLVO model & 0 & $3.0 \times 10^{-20}$ & 0 & $3.0 \times 10^{-20}$ & 0 & $3.0 \times 10^{-20}$ & 0 & $2.9 \times 10^{-20}$ \\
\hline Steric model & - & $3.0 \times 10^{-20}$ & 77,500 & $3.0 \times 10^{-20}$ & 77,300 & $3.0 \times 10^{-20}$ & 82,200 & $2.9 \times 10^{-20}$ \\
\hline \multicolumn{9}{|l|}{ E. faecalis-PTFE } \\
\hline DLVO model & 0 & $2.9 \times 10^{-20}$ & 0 & $2.9 \times 10^{-20}$ & 0 & $2.8 \times 10^{-20}$ & 0 & $2.8 \times 10^{-20}$ \\
\hline Steric model & - & $2.9 \times 10^{-20}$ & 79,400 & $2.9 \times 10^{-20}$ & 81,300 & $2.8 \times 10^{-20}$ & 86,200 & $2.8 \times 10^{-20}$ \\
\hline
\end{tabular}

${ }^{\mathrm{a}}$ For the control condition (i.e., no PAC), only the DLVO model was used for the interaction energy calculations.

$\mathrm{b}$ " 0 " indicates that no energy barrier is predicted for this condition.

${ }^{\mathrm{c}}$ The DLVO model considers the sum of equations 1 and 7.

${ }^{\mathrm{d}}$ The Steric model considers the sum of equations 1, 7 and 11 . 
Table 3. Summary of the estimated depths of the secondary energy minimum

\begin{tabular}{|c|c|c|c|}
\hline \multirow[b]{3}{*}{ Bacteria-Biomaterial System } & \multicolumn{3}{|c|}{ Estimated Depths of Secondary Energy Well $\left(V_{\mathrm{w}}\right)$} \\
\hline & \multicolumn{3}{|c|}{ Treatment $^{\mathrm{a}}$} \\
\hline & BAC & MAT & BOTH \\
\hline \multicolumn{4}{|l|}{ E. coli-PVC } \\
\hline depth of secondary minimum $(k T)$ & -279 & -276 & -98 \\
\hline$h(\mathrm{~nm})^{\mathrm{b}}$ & 4.6 & 4.6 & 10 \\
\hline \multicolumn{4}{|l|}{ E. coli-PTFE } \\
\hline depth of secondary minimum $(k T)$ & -267 & -250 & -89 \\
\hline$h(\mathrm{~nm})$ & 4.6 & 4.6 & 10 \\
\hline \multicolumn{4}{|l|}{ E. faecalis-PVC } \\
\hline depth of secondary minimum $(k T)$ & -116 & -117 & -41 \\
\hline$h(\mathrm{~nm})$ & 4.6 & 4.6 & 10 \\
\hline \multicolumn{4}{|l|}{ E. faecalis-PTFE } \\
\hline depth of secondary minimum $(k T)$ & -111 & -106 & -37 \\
\hline$h(\mathrm{~nm})$ & 4.6 & 4.6 & 10 \\
\hline
\end{tabular}

${ }^{a}$ For the control condition (i.e., no PAC), the DLVO model was used for the interaction energy calculations and predicts no energy barrier to deposition and therefore no secondary energy minimum.

${ }^{\mathrm{b}}$ The separation distance $(h)$ where the secondary energy minimum is located. 


\section{Figure Captions}

FIG. 1. (a) QCM measurements (i.e., crystal resonance frequency, $3^{\text {rd }}$ overtone) for PAC adsorption onto a PVC coated quartz crystal. Phase I: baseline is obtained by flowing PBS over the crystal surface; phase II: PAC-PBS is injected (100 $\mu \mathrm{g} / \mathrm{mL})$; phase III: PBS is injected; phase IV: $0.1 \%$ Hellmanex is injected. (b) The measured frequency shift is converted to adsorbed mass per unit area of the sensor crystal using the Sauerbrey relationship.

FIG. 2. Average number of adhered cells per square centimeter on a biomaterial disk following a PPFC experiment for (a) E. coli CFT073, and (b) E. faecalis 29212. Conditions are abbreviated as control (CTRL), PAC treatments of both biomaterial and bacteria (BOTH), PAC treatment on biomaterial alone (MAT), and PAC treatment of bacteria alone (BAC). Error bars represent standard deviations. All data for a given biomaterial are statistically different between each condition $(p<0.01)$, with the exception of the "MAT" and "BAC" conditions for E. coli on PTFE.

FIG. 3. Average number of adhered particles per square centimeter on a biomaterial disk following a PPFC experiment for $1 \mu \mathrm{m}$ latex microspheres. Conditions are abbreviated as control (CTRL), PAC treatments of both biomaterial and particles (BOTH), PAC treatment on biomaterial alone (MAT), and PAC treatment of particles alone (PART). Error bars represent standard deviations. All data for a given biomaterial are statistically different between each condition $(p<0.01)$.

FIG. 4. Representative microscope images (20x magnification) of PTFE surface following flow cell experiments with latex microspheres (a) in the absence of PAC ("CTRL" condition), and (b) in the presence of PAC ("BOTH" condition).

FIG. 5. Representative calculated interaction energy plotted as a function of separation distance for $E$. coli approaching a flat PVC surface using (a) the DLVO model; (b) the Steric model; and (c) the Steric model replotted on a different scale to highlight the presence of the secondary energy well. Measured zeta potentials (Table 1) and calculated Hamaker constants (Table 2) were used to determine interaction energies. 

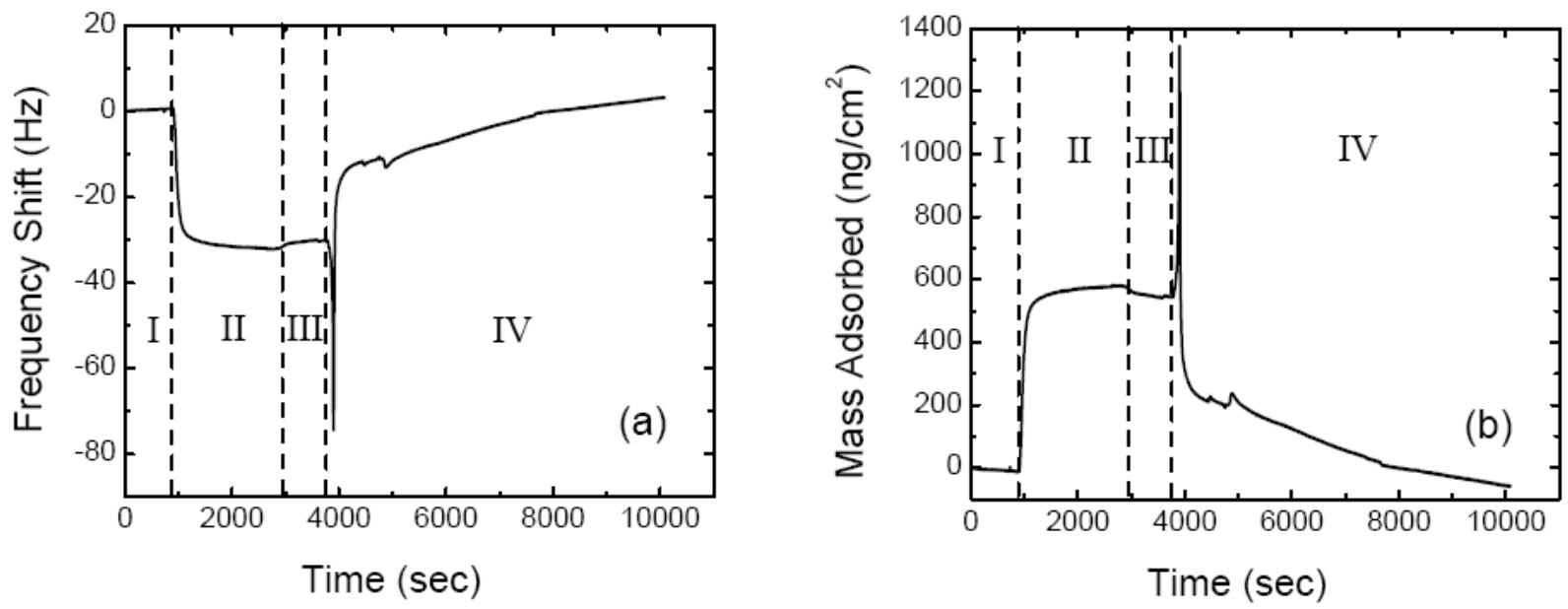

Eydelnant and Tufenkji FIGURE 1 

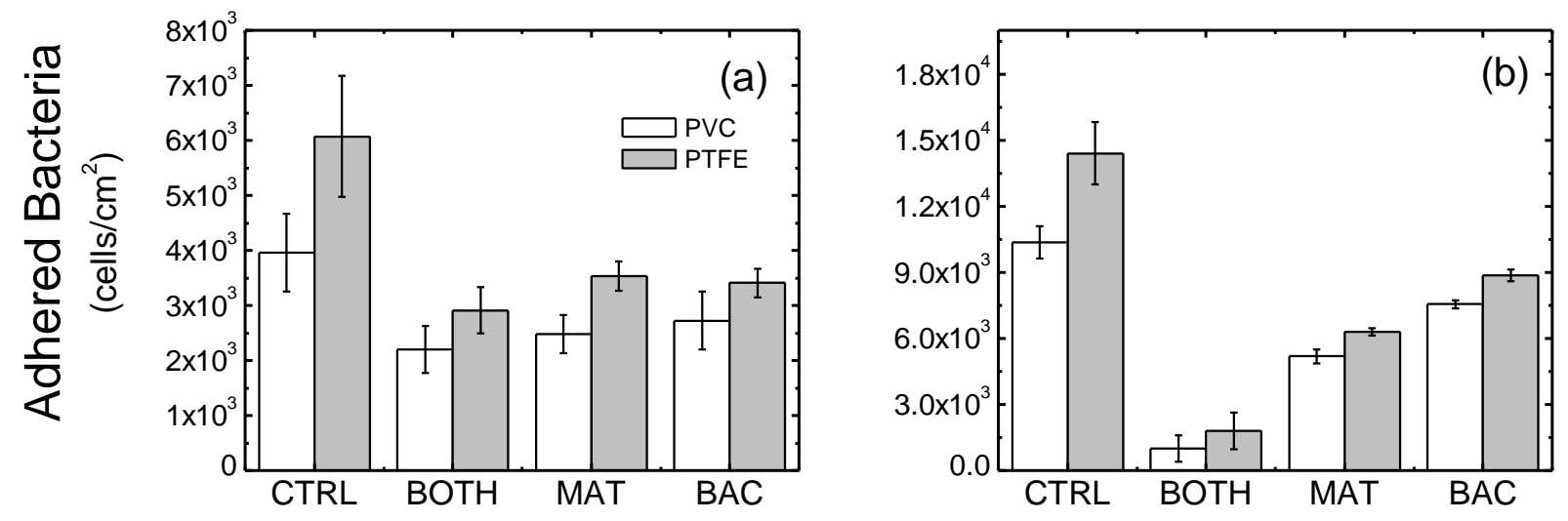

Eydelnant and Tufenkji FIGURE 2 


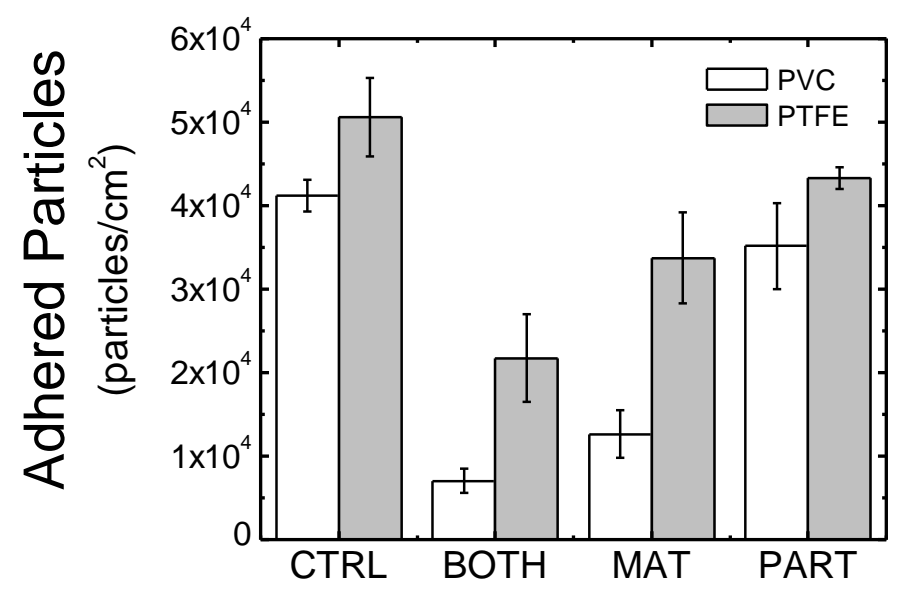

Eydelnant and Tufenkji FIGURE 3 

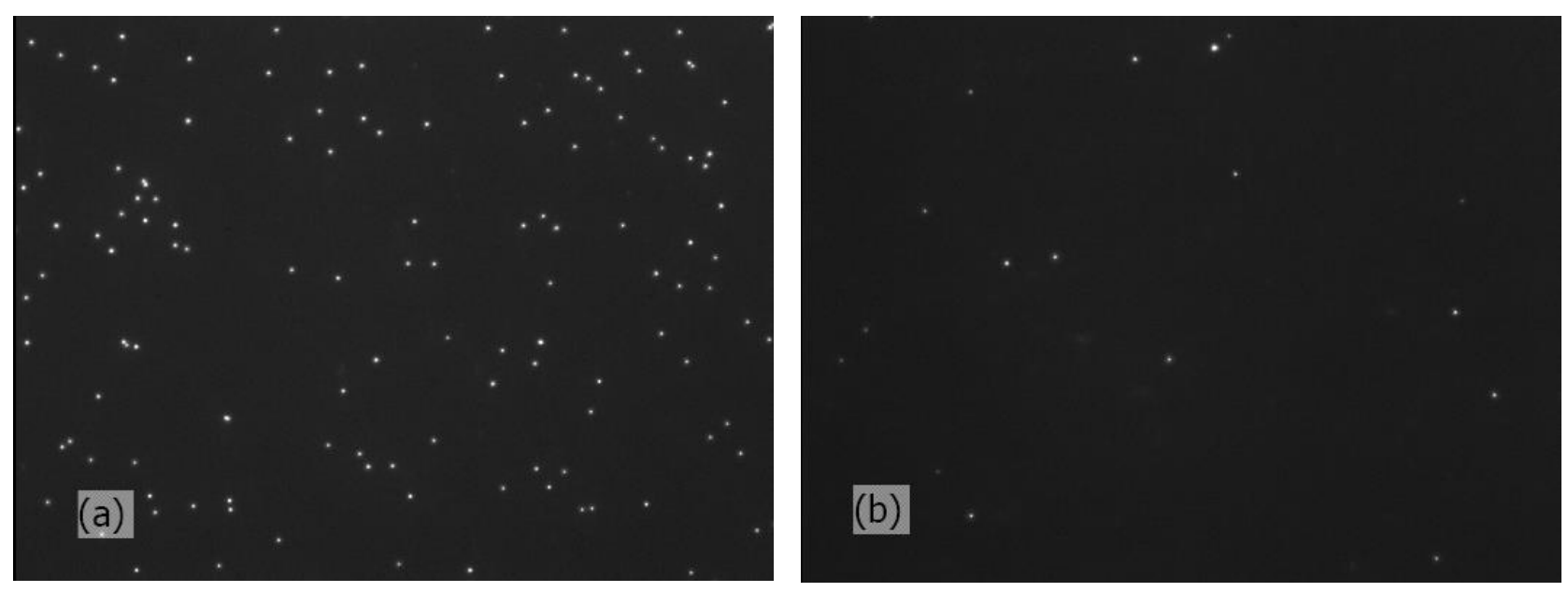

Eydelnant and Tufenkji

FIGURE 4 

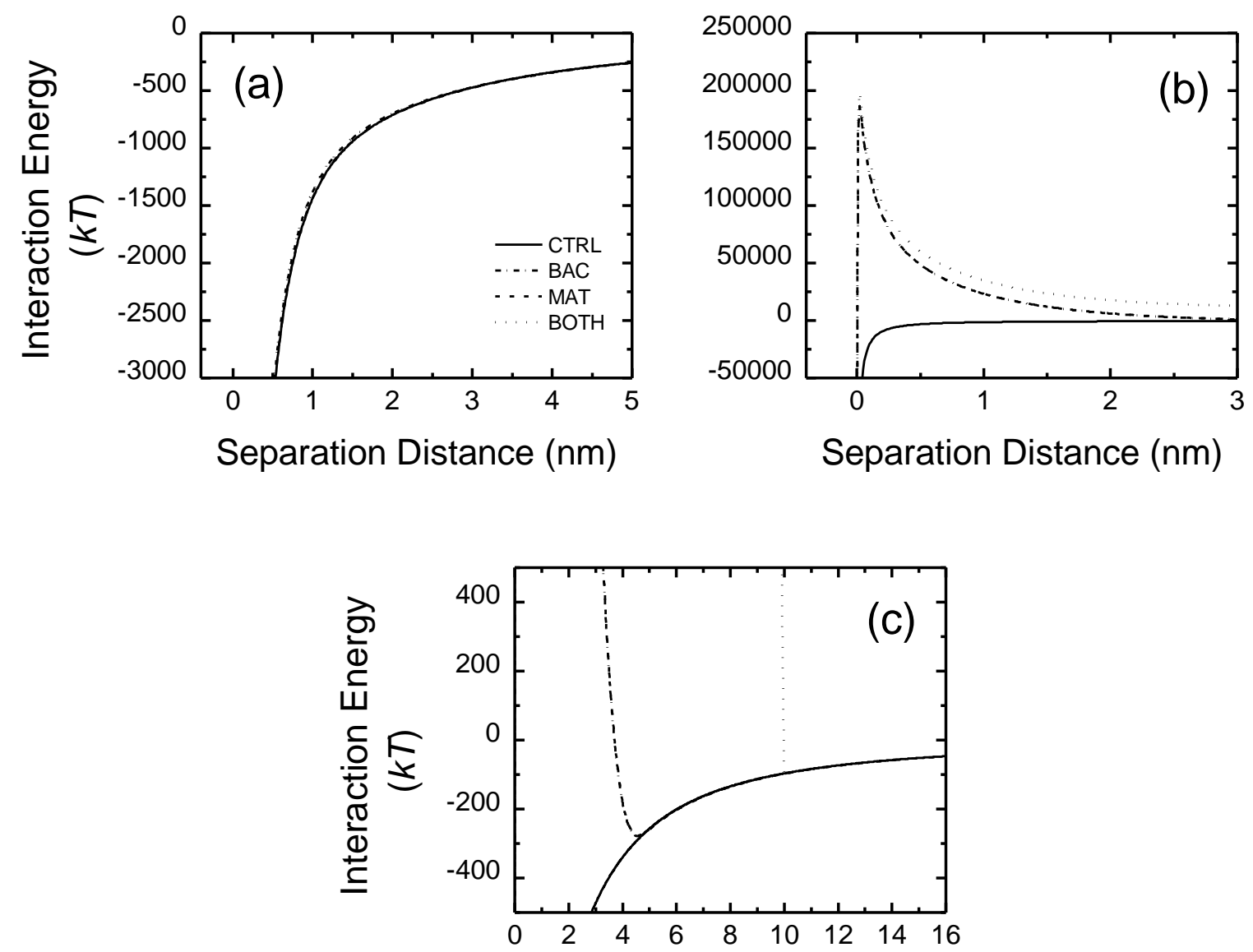

Separation Distance (nm)

Eydelnant and Tufenkji

FIGURE 5 


\section{FOR TABLE OF CONTENTS USE ONLY}

TITLE: Cranberry Derived Proanthocyanidins Reduce Bacterial Adhesion to Selected Biomaterials

AUTHORS: Irwin Adam Eydelnant and Nathalie Tufenkji
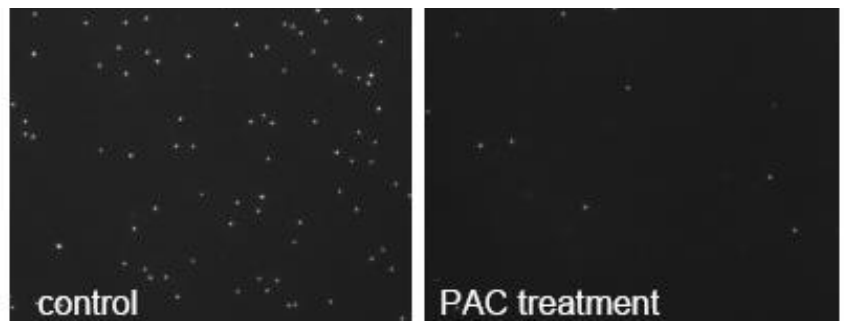